\title{
Dos conjuntos às alegorias
}

\section{NÍLSON JOSÉ MACHADO}

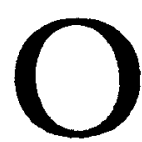

s objetos matemáticos já representaram, através dos séculos, os mais diferentes papéis na constituiçăo e na organização do conhecimento. $\mathrm{Na}$ antigüidade grega, uma tradiçăo associada a Pitágoras procurou explicar o mundo a partir de referências a quantidades numéricas: a harmonia musical, o corpo humano, os corpos celestes, tudo poderia ser traduzido e representado por números e de tal representaçáo extraíam-se, inclusive, argumentos para a plausibilidade das relaçóes percebidas.

Em Platáo, a célebre frase que ornamentava sua Academia "Não entre aqui quem não conhecer Geometria" é um testemunho da confiança nos objetos e nas relaçóes geométricas para representar o mundo sensível e suas articulaçóes. O estatuto ontológico do mundo empírico platônico, no entanto, era reduzido ao de mera cópia ou realizaçáo imperfeita do mundo das idéias, constituído, em última instância, pelas idéias matemáticas, como a idéia de círculo, e as de natureza moral, como a idéia de bem.

Aristóteles restaura em parte a dignidade do mundo empírico, revigorando o significado do predicado, da qualidade, como contraponto para certa superestimaçáo das relaçóes numéricas, do quantitativo, presente em muitos de seus antecessores.

Particularmente no que tange à concepçáo de linguagem, Aristóteles distanciou-se sobremaneira das concepçóes pitagóricas e das platônicas, deslocando o centro de gravidade da representação e da justificaçáo do conhecimento da segurança e da estabilidade da linguagem matemática para a riqueza e o movimento da língua grega.

De fato, em tal terreno é que se enraíza a lógica formal, que expressa fielmente as formas predicativas, as categorias delineadas pela língua grega. Tal deslocamento náo significa, naturalmente, um banimento do quantitativo das elaboraçóes aristotélicas: na verdade, em toda sua obra, Aristóteles entretece elementos associados ao trabalho do classificador, do caçador, do esculápio, do que valoriza, enfim, os sintomas, juntamente com outros elementos de raízes platônicas, como a tentaçáo das formas fixas para as proposiçóes ou os argumentos, ou da universalidade das categorias. 


\section{Os séculos XVII, XVIII e XIX}

Existe um razoável consenso, no entanto, quanto a certo predomínio da qualidade sobre a quantidade na epistemologia aristotélica. Ressalvando-se aqui e ali exceçóes que apenas confirmam a regra, tal predomínio persistiu durante praticamente toda a Idade MÉdia, desaguando no limiar da ciência moderna, quando despontam trabalhos como os de Galileu, Descartes, Locke, Leibniz, Newton, entre outros.

Embora em tais pensadores a força do qualitativo subsista, para transcender as concepçóes aristotélicas foi fundamental o recurso a certas idéias platônicas, assim como uma maior valorização das relaçōes quantitativas.

Assim, a Geometria cartesiana ou o Cálculo de Newton ou de Leibniz, não obstante apresentem-se, segundo os olhos dos séculos seguintes, eivados de qualidades inexplicáveis ou desnecessárias, caminham para uma progressiva assepsia, com o predomínio crescente dos aspectos quantitativos.

Em Kant, já no século XVIII, entrelaçam-se e amalgamam-se elementos qualitativos e quantitativos de uma forma fecunda e original. Por um lado, as categorias kantianas significam um retorno às intençóes predicativas aristotélicas; por outro, seu importante ensaio sobre o uso das magnitudes negativas na Filosofia (Kant, 1992) parece um indício veemente do fascínio exercido pelos aspectos quantitativos do conhecimento.

No século XIX, os grandes sucessos da matematização da Física, com Fourier e a Teoria do Calor, ou Maxwell e as equaçóes do Eletromagnetismo, contribuíram decisivamente para a fixação de uma imagem de onipotência das relaçóes numéricas e funcionais, com o predomínio das quantidades sobre as qualidades. A frase platônica sobre os poderes da Geometria transfigura-se, entáo, na máxima de Rutherford Qualitative is notbing but poor quantitative.

As pretensóes de irredutibilidade entre o qualitativo e o quantitativo, ou de hegemonia de um dos membros do par, constituem elementos de um cenário em que se desenharáo duas vertentes extremamente fecundas para a problematizaçáo das relaçóes entre os objetos matemáticos e a constituiçăo do conhecimento: por um lado, uma radicalizaçăo na distinģăo entre ciências bumunnes e ciências axatas surge associada a certa tentativa de legitimação da dualidade qualidade/quantidade, conduzindo a diferenciaçóes supostamente paradigmáticas, como a relativa aos pares explicagáio/ciências exatas, compreensáo/ciências bumanas; por outro lado, no interior da Matemática, a emergéncia da 
Teoria dos Conjuntos, na segunda metade do século XIX, fornece os ingredientes básicos para uma aproximaçáo até entáo insuspeitada entre o qualitativo e o quantitativo, favorecendo o grande desenvolvimento de uma Matemática qualitatipa cuja irradiação para as ciências constituídas ou em desenvolvimento náo tardou a ocorrer.

Abdicar-se-á, aqui, de uma análise mais demorada da primeira das vertentes, para uma concentraçáo de esforços no exame das possibilidades e dos limites da Teoria dos Conjuntos na constituiçáo da Matemática, das Ciências e no próprio funcionamento da linguagem natural. Buscar-se-á também uma análise de instrumentos mais abrangentes, elaborados enquanto objetos matemáticos posteriormente à Teoria dos Conjuntos, como as Estruturas, as Categorias, as Alegorias, que podem ter um significado importante na construção, na organização e na justificação do conhecimento.

\section{Conjuntos, Estruturas, Categorias}

Inicialmente, $\in$ bom que se registre, a despeito do otimismo acentuado de muitos matemáticos no que tange ao papel a ser desempenhado pela Teoria dos Conjuntos como linguagem unificadora da $\mathrm{Ma}$ temática e na fundamentaçáo axiomática das Ciências em todas as áreas e em todas as etapas de seu desenvolvimento, que tal expectativa nem de longe parece consensual. A razăo básica é que tal teoria permanece tributária de uma ontologia demasiadamente estreita: os elementos de um conjunto, caracterizados por um único predicado, sáo objetos claros, distintos, perfeitamente definidos, esgotando-se no âmbito de uma única relaçáo, a de pertinência.

Uma análise especialmente interessante das limitaçóes da Teoria dos Conjuntos, criada por Cantor na segunda metade do século XIX, realizada por Castoriadis $(1987$, v.2). Segundo Cantor, "um conjunto é uma reunião em um todo de objetos definidos e distintos de nossa intuiçáo ou de nosso pensamento. Esses objetos são denominados os elementos do conjunto" (Apud Castoriadis, 1987, v.2:395).

A possibilidade da consideraçáo de objetos definidos e distintos em universos menos assépticos do que o matemático sempre revelou-se problemática. Úma frase do próprio Cantor, em carta enviada a Dedekind (28 jul. 1899) serve de mote para as consideraçóes de Castoriadis: "toda multiplicidade é ou uma multiplicidade inconsistente ou um conjunto" (Apud Castoriadis, 1987, v.2:394).

Ocorre que justamente essas multiplicidades irrconsistentes do ponto de vista da lógica formal sáo de grande interesse no mundo humano, 
constituindo a regra no universo das significaçōes sociais; a elas, entáo, o filósofo dedica sua atençăo, năo ignorando, o que seria absurdo, a dimensão conjuntista da linguagem, mas evidenciando suas limitaçóes intrínsecas do ponto de vista da ontologia subjacente.

Com o advento das Estruturas, ocorre um primeiro movimento importante no sentido de associar-se aos objetos matemáticos uma ontologia mais rica. De fato, num primeiro momento, ocorre uma ampliação significativa no espectro de tais objetos: números, grandezas, figuras, passam a dividir as atençóes com vetores, matrizes, permutaçóes, proposiçóes etc; tais novos objetos passam a constituir sistemas, caracterizados por propriedades, por feixes de relaçóes; posteriormente, os próprios sistemas multiplicam-se, transfiguram-se, sem perder suas características básicas, suas propriedades fundamentais, ocorrendo, então, um notável deslocamento das atençóes dos objetos para as relaçóes constitutivas.

De fato, uma estrutura é um conjunto onde os elementos estáo relacionados através de uma, às vezes, duas operaçóes, que apresentam certas propriedades muito simples, como o fechamento ou a associatividade, por exemplo. Tais operaçôes articulam entre si os elementos do conjunto, de modo a compor uma totalidade com nível de organizaçáo superior ao de um simples conjunto, no qual tudo o que se exige de um objeto é uma prontidão absoluta na resposta à questăo da pertinência.

A noçáo de estrutura enquanto objeto matemático desenvolveu-se intensamente no interior da Matemática e frutificou nos mais variados terrenos, como os da Lingüística, da Antropologia, da Física, da Filosofia, entre outros, sobretudo nas décadas de 50 e 60 . Lévi-Strauss e suas estruturas de parentesco, ou dos mitos, constitui apenas um exemplo, ainda que notável, do poder de sedução de tal objeto.

O enriquecimento das relaçóes características de uma estrutura, tanto no que se refere à natureza das operaçóes quanto no que tange às propriedades a que deviam satisfazer, conduziu a uma progressiva complexidade das mesmas e a certa classificação/hierarquizaçáo desses objetos a partir de estruturas básicas, consideradas por Bourbaki como estruturas-mãe, como são as estruturas algébricas, as estruturas de ordem e as estruturas topológicas, desenvolvendo-se uma grande variedade de formas no âmbito de cada tipo.

Esse florescimento da noçáo de estrutura, que tem em seu cerne o deslocamento das atençóes do ser enquanto esstncia para os objetos articulados por sistemas de relações, subjaz à disseminação dos estruturalismos de todos os quilates nas mais variadas áreas e conduziu, no 
interior da Matemática, a uma espécie de teoria das estruturas. Nesta, a meta passa a ser o estabelecimento de relaçóes gerais, que vigem em diferentes estruturas, independentemente dos objetos que articulam. Não é outro o caminho que conduz à emergência da Teoria das Categorias, a partir dos anos 60 .

Com as Categorias, ocorre, entáo, um deslocamento decisivo nas atençōes dos entes para as relaçōes; à medida em que têm por objetos as estruturas matemáticas, os próprios objetos passam a ser constituídos por sistemas de relaçóes. Isto conduz à emergência de uma fecunda dualidade entre objetos e relaçóes.

De fato, numa categoria há objetos e há relaçóes, que são os morfismos, mas os objetos podem ser perfeitamente caracterizados pelo feixe de relaçōes nele incidentes ou dele emergentes. É mesmo possível afirmar-se que bastam os morfismos para caracterizar uma categoria, algo equivalente a dizer-se dize-me que transformajóes realizas e te direi que categorias utilizas; as mais modernas definiçóes de categoria explicitam apenas as características dos morfismos correspondentes.

A riqueza da teoria das categorias, quando comparada com a da teoria dos conjuntos, conduziu a maior parte dos matemáticos a considerá-la uma extensáo natural da linguagem conjuntista, fazendo-a depositária de todas as expectativas de unificaçăo da Matemática através da universalizaçáo da linguagem que utiliza. Paralelamente, desenvolveram-se noçóes como as de feixe ou de topos, dedicadas a dar respostas a agudas questóes relacionadas com a passagem de resultados locais a resultados globais, no âmbito das relaçóes, ou à possibilidade de formalizaçáo da idéia de algo como uma estrutura paridipel, no âmbito dos sistemas. Tais noçóes, no entanto, ainda se encontram muito distantes de uma utilização expressiva fora das searas técnicas das quais emergiram.

\section{Piaget e as Categorias}

Como já ocorrera com os Grupos e as Estruturas em geral, no caso das Categorias, é novamente no âmbito do referencial piagetiano que surgem as tentativas pioneiras de exploraçáo do novo objeto externamente ao terreno matemático, na constituiçăo/organizaçáo do conhecimento.

De fato, se o desenvolvimento da álgebra ocorrido nos anos 30 inspirou os primeiros trabalhos piagetianos, conduzindo-o a situar a estrutura de grupo no centro de suas atençóes e atividades, se os trabalhos do grupo Bourbaki, nos anos que sucederam a Segunda Guerra 
Mundial, privilegiando a noção de estrutura como instrumento fundamental na própria arquitetura da Matemática, tornaram Piaget um estruturalista convicto, seria, talvez, previsível, sua adesáo entusiástica ao novo instrumento, que surge como uma generalizaçáo natural da noçáo de estrutura, como uma teoria geral das estruturas.

No âmbito do referencial piagetiano, é significativa a contribuiçăo de Papert para o deslocamento das atençóes das estruturas para as categorias. Seu artigo Structures et Catégories (1969) 6 fecundo e esclarecedor, tanto no que se refere ao conteúdo examinado quanto no que tange ao esclarecimento sobre o fato de o interesse de Piaget pelo tema ser consequiência natural das pressuposiçóes básicas de sua epistemologia genética.

Lamentavelmente, não restou muito tempo ao mestre genebrino para a exploração da nova seara; tendo falecido em 1980, apenas dez anos depois, na Suíça, é publicada uma coletânea de trabalhos de Piaget e de quase duas dezenas de seus colaboradores, na qual a noçáo de categoria ocupa a posiçáo central, explicitando-se de modo claro e convincente sua natural vinculação com a epistemologia genética. Em Morphismes et Cattgories, um novo ciclo de atribuiçŏes de significados aos objetos matemáticos na representação e na justificação do conhecimento parece ter início. Em especial, o capítulo intitulado Teoria das Categorias e Epistemologia Genetica é lúcido e equilibrado, devendo tornar-se leitura básica de todos os que se pretendem piagetianos. Nele, Ascher afirma: "Eu tentei tornar plausível - em grandes linhas - a idéia de que a teoria das categorias, considerada como teoria das construçóes matemáticas, reflete a constituição genética dos instrumentos cognitivos humanos: o desligamento de esquemas transferíveis de um conjunto de açôes, seguido de operaçóes semelhantes sobre esses esquemas, seguidas de operaçóes sobre esquemas de esquemas e assim por dianten (1990:217).

\section{Categorias, Alegorias}

Coincidentemente, no mesmo ano em que é publicado Morphismes et Catégories, ocorre no interior da Matemática o que parece ser um novo salto qualitativo, com a entrada em cena da noçáo de Alegoria, uma generalização da noção de categoria elaborada por Freyd e Scedrov (1990).

Em uma alegoria também existem objetos e relaçóes; essas, no entanto, enquanto instrumentos correlatos aos morfismos, deixam de representar necessariamente funçóes, ou seja, de ter necessariamente uma orientaçáo da origem para a extremidade, passando a constituir 
elos, arcos de ligação, relações em sentido mais amplo. Em outras palavras, numa alegoria, os objetos constituem feixes de relações que incorporam as relaçóes funcionais, ou as causais, mas que incluem também interaçóes de outros tipos, como as relaçóes analógicas, ou mais genericamente, associações do tipo dizer $B$ para significar $A$, sem que se afirme que $A$ implica $B$ ou que $B$ implica $A$.

Convém notar que, no percurso dos conjuntos às alegorias enquanto objetos matemáticos para a representação do conhecimento, paralelamente ao enriquecimento das técnicas, houve considerável transformação na ontologia subjacente à utilizaçăo dos correspondentes objetos, resultante tanto do progressivo deslocamento das atençóes dos entes para as relaçóes, quanto do fecundo alargamento da noção de relação.

Ainda que possa ser associada a processos inconscientes, de um ponto de vista filosófico, ou a um efeito não planejado, do tipo serendipty, a ampliação no significado do termo relação parece extremamente importante do ponto de vista epistemológico. Provavelmente, tal alargamento teria impedido Jung, um mestre do pensamento analógico, de afirmar, de forma tão magoada e contundente, que a Matemática não teria a ver com o desenvolvimento do raciocínio lógico; no quadro conceitual junguiano, o lógico parecia excluir o analógico.

No caso específico das alegorias, as repercussóes de tal objeto fora do âmbito da Matemática ainda não são suficientemente visíveis, ou são praticamente inexistentes. Alguns de seus aspectos mais desafiadores são o reexame da noção de causalidade e o desenvolvimento da concepçáo de conhecimento como rede de significaçóes, como alternativa para as cadeias causais, mesmo as que se disfarçam em árvores ou estruturas hierárquicas.

Do ponto de vista epistemológico, uma perspectiva menos otimista na análise da importância do percurso dos conjuntos às alegorias como instrumentos matemáticos para a representação do conhecimento, a despeito do enriquecimento ontológico já referido, sugere a existência de uma vinculação estreita entre a linguagem categórica - ou alegórica - e a linguagem conjuntista, da qual as outras permaneceriam tributárias. Tal ponto de vista parece relevante e mereceria uma análise cuidadosa.

\section{Alegorias: alternativas}

De modo mais freqüente, no entanto, surgem diversos focos de críticas relativamente às possibilidades e aos limites da matemática con- 
juntista na constituiçăo das Ciências e no funcionamento da linguagem natural. Tais criticas, no entanto, deveriam levar em conta um quadro epistemológico mais atualizado, assimilando os desdobramentos naturais da linguagem conjuntista, como são as categorias ou as alegorias; freqüientemente não o fazem.

É comum, entáo, o surgimento de objetos alternativos, aparentemente fecundos, para a representaçăo do conhecimento, mas que pagam um alto preço, sobretudo em termos operacionais, pela ignorância dos novos objetos matemáticos. Esses objetos alternativos, em decorrência de tal ignorância, internamente à Matemática, talvez não sejam levados suficientemente a sério; externamente a ela e sem o seu apoio, em razáo de uma inevitável complexidade, talvez não sejam suficientemente compreendidos.

No que se refere às críticas à linguagem conjuntista, um exemplo vigoroso é o de Castoriadis (1987), em As encruzilhadas do labirinto. De seu trabalho, surge com força a interessante noção de magma, elaborada para a representaçáo de objetos do conhecimento que náo se esgotam em conjuntos, como seriam, por exemplo, as significaçóes sociais.

Para Castoriadis, um magma é um objeto caracterizado pelas seguintes propriedades:

"Ml: Se M é um magma, pode-se identificar em $M$ um número indefinido de conjuntos.

M2: Se M é um magma, pode-se identificar em $M$ outros magmas diferentes de $M$.

M3: Se $M$ É um magma, não existe partiçáo de $M$ em magmas.

M4: Se M é um magma, toda decomposiçáo de $M$ em conjuntos deixa como resíduo um magma.

M5: O que năo é um magma ou é um conjunto ou năo é nadan (p.404).

As fecundas consideraçōes de Castoriadis mereceriam uma análise atenta, tanto por parte de matemáticos como por parte de não-matemáticos. Seria interessante tentar-se uma articulação mais consistente entre suas críticas e os recursos associados aos objetos matemáticos mais recentemente desenvolvidos, alguns deles com origem posterior à maior parte dos trabalhos de Castoriadis. Particularmente no que se refere à natureza dicotômica da definiçăo de magma, caracterizado sinteticamente como um năo-conjunto, parece possível preencher uma parte substantiva do abismo que se supóe existir entre magmas e conjuntos 
recorrendo-se a objetos matemáticos como feixes, topoi, categorias, alegorias, entre outros.

\section{Conhecimento como Rede}

Não parece inteiramente razoável, no entanto, alimentar-se expectativas excessivamente otimistas com relação a um reconhecimento natural das possibilidades epistemológicas desses novos objetos matemáticos; sem uma transformaçáo correlata na concepção de conhecimento que subjaz à organizaçáo escolar ou acadêmica, tais instrumentos podem permanecer adormecidos como sofisticados computadores, utilizados apenas como máquinas de escrever.

De fato, juntamente com o desenvolvimento dos novos instrumentos de representaçáo do conhecimento, é necessário reelaborar a própria concepçăo de conhecimento, desviando-a mais e mais de balizas como conjuntos bem definidos, classificaçóes estáveis, árvores ou estruturas hierárquicas imutáveis, cadeias causais linearmente condicionadas e aproximá-la decisivamente de um novo paradigma, qual seja, o de uma rede em um espaço de representaçóes.

Em As tecnologias da inteligencia, Lévy (1993) caracteriza três tempos, três dimensóes das tecnologias da informaçăo, que se superpóem, coexistem, entrelaçam-se e interagem continuamente: a oralidade, cuja imagem geométrica é o círculo; a escrita, que tem como representação a linha reta; e o hipertexto, uma síntese de recursos e significaçóes múltiplas, multiplamente entrelaçadas, cuja imagem representativa é a de uma rede.

A partir de tal rede de significaçóes, constituída de nós e conexōes, onde um nó é resultante da conexão de diversos fios e as conexóes são caracterizadas pela referência aos nós que interligam, elabora-se operacionalmente a diluição dos objetos em relaçōes $e$, reciprocamente, a consubstanciaçáo de relaçóes em objetos.

Assim, à medida que perde força a distinçáo nítida entre objetos e relaçóes, configura-se com mais clareza certa dualidade entre os elementos desse par, na qual os objetos são percebidos/concebidos como feixes de relaçóes e feixes de relaçóes sáo transformados em novos objetos; as relaçóes são determinadas por pares de objetos e cada objeto é caracterizado pelas relaçóes nele incidentes ou dele emergentes.

O reconhecimento de tal dualidade parece absolutamente fundamental para uma caracterizaçáo mais nítida das relaçóes entre o concreto e o abstrato no processo de construçáo do conhecimento. É possível que 
o próprio Marx tenha vislumbrado isso, ao afirmar que o concreto é concreto por ser uma síntese de múltiplas determinaçóes.

\section{Conseqüências pedagógicas}

No terreno de tais concepçóes, germinam sementes de um grande número de temas de natureza pedagógica, como são as elaboraçóes curriculares, a organizaçáo do trabalho escolar, o planejamento da açáo docente, os processos de avaliaçáo. Disciplinas, interdisciplinaridade, valores, avaliaçáo, tecnologias, inovaçóes são temas permanentemente tributários de uma concepçăo de conhecimento. Um exemplo candente de como uma tal concepçáo sobressai no cenário educacional sáo as freqüentes declaraçōes de adesáo ao construtivismo, em geral desprovidas de contrapontos legitimadores ou carentes de uma fundamentaçăo mínima.

Um programa de pesquisa que busque explicitar concepçóes de conhecimento que subjazem ao trabalho escolar, associadas aos objetos matemáticos que as representam $\mathbf{e}$ articuladas com as correspondentes ações de natureza pedagógica, poderá ter um significado pedagógico profundo.

Em passado recente, falar-se de alegorias em matemática significava apenas a eventual utilização do sentido figurado como um recurso didático para a compreensão de seus objetos; hoje, as alegorias constituem sofisticados objetos matemáticos que permitem a quem os manuseia a caracterizaçáo de teorias formais como alegorias (Freyd \& Scedrov, 1990:275) ou a referência a resultados como o teorema da metonimia (ibid.:246).

Paulatinamente, cresce a percep̧ão de que objetos matemáticos considerados complexos e abstratos, como categorias ou alegorias, constituem instrumentos muito mais adequados do que os insípidos conjuntos para a representação do conhecimento em qualquer área. $\mathrm{Na}$ mesma medida, deve sedimentar-se a concepçáo epistemologicamente fecunda de que a persistência e a continuidade na elaboraçáo do conhecimento não conduzem a um distanciamento crescente, mas significam, efetivamente, uma progressiva aproximação da realidade.

\section{Referências Bibliográficas}

CASTORIADIS, Cornelius. As encruzillbadas do labirinto (3 v). Rio de Janeiro, Paz e Terra, 1987. 
FREYD, Peter \& SCEDROV, Andre. Categaries, allegories. Amsterdam, North Holland, 1990.

GARDNER, Howard. Multiple intelligences. New York, Basic Books, 1993.

KANT, Immanuel. Opísculos de filosofia natueral. Madrid, Alianza Editorial, 1992.

LÉVY, Pierre. As tecnologias da inteliglncia. Rio de Janeiro, Editora 34, 1993.

PAPERT, Seymour. Structures et categories. In: Logique ot connaissance sciontiffque. Enciclopedic de la Pleiade. Paris, Gallimard, 1969.

PIAGET, Jean et alii. Morpbismes ct cattgories. Paris, Delachaux \& Niestle, 1990.

THOM, René. Qualidade/quantidade. In: Dialecticar. Encicloptdia Einaudi, v.10. Porto, Imprensa Nacional/Casa da Moeda, 1985.

\title{
Resumo
}

O autor discute o significado da utilizaçāo de objetos matemáticos na representaçáo do conhecimento. Começando com os números, passa sucessivamente a outros instrumentos formais, como conjuntos, estruturas, categorias, e um novo objeto matemático propasto por Freyd \& Scedrov (1990), as alegorias. Sugere que, neste percurso, o crescimento no nível de abstraçāo dos objetos não conduz necessariamente a um distanciamento crescente, mas significa, pelo contrário, uma progressiva aproximação da realidade.

\begin{abstract}
The Author discusses the meaning of the use of mathematical objects in representing knowledge. Starting with numbers, he examines sucessively others formal instruments, such as sets, structures, categories, and allegories, a new object proposed by Freyd \& Scedrov (1990). This way, he suggests that the growth of the abstraction level does not presuppose a necessary progressive disconnection from reality; quite the contrary, it provides an increasing contact with it.
\end{abstract}

Nilson José Machado é professor da Faculdade de Educação da Universidade de Sáo Paulo e professor-visitante do Instituto de Estudos Avançados da USP no Programa Educação Para a Cidadania. 